\title{
The difference supervision theory of engineering registration workers based on Bayesian inference
}

\author{
Zhijiang FENG ${ }^{1}$, Jiancheng $\mathrm{LIU}^{1}$, Limin WANG ${ }^{1}$, Hongliang Zhang ${ }^{1}$, Ping ZHANG ${ }^{2}$ \\ ${ }^{1}$ Hebei Institute of Architecture and Civil Engineering \\ ${ }^{2}$ China life insurance \\ e-mail:wlmfirst@sina.com
}

\begin{abstract}
At present, during the process of architecture market management information, it is necessary to use the difference supervision theory, which can improve the efficiency of the supervision, save the supervision resource and reduce the supervision cost. According to the research status of the difference supervision theory, Bayesian inference theory is proposed to verify an engineering registration worker whether an affiliated worker or not. And a example is presented.
\end{abstract}

Keywords-Bayesian Inference Theory, The difference supervision, affiliated, architecture market management information

I. THE ENGINEERING BACKGROUND OF THE DIFFERENCE SUPERVISION THEORY

Due to the construction engineering related to many things, the construction process is a complicated synthetically process. Adding to the fixed place, the ambulatory production, the different structures, the quality requests, the different construction methods, the large figure, the holistic, the long periods, and it is decided by natural conditions, it is more difficult to control the quality of the construction than other industry productions. Absolutely, the constructor is important to insure the quality of the construction[1].

From 1994, the ministry of construction studied the system of constructor registration. Construction law of the people's republic of china (1997) has clearly stipulated the technical personnel who engages in construction, should obtain the licensed qualification certificate by law, and engages construction in range of the licensed qualification certificate permissive. The ministry of personnel and construction print and distribute the provisional regulation of constructor qualification system, it contains that the country implements the qualification system on the technical personnel who is the Construction General Contract and the key station of the construction manage.

The qualification system on the technical personnel can put the responsibility to the human, if the great quality and safety accident or the illegal behaviors was happened, not only the responsibility of the corporation is run by law, bur also the responsibility of the technical personnel is run according to the law. So implementing the qualification system is propitious to the architecture market order, and ensures the engineering quality and building safety [2].

But the affiliated constructors are more and more common, this phenomenon developed from the coastal city to the northwestern, and to the whole country. For the windfall, some headhunters are appeared to help the constructors. As the www.nxgkw.com, it is a professional construction headhunter [3]. So it is indispensable to make the architecture market management information.

The architecture market management information can make the management standardization and the decision scientific. It also can improve the administration efficiency and the supervision ability, and reduce the manage cost. According to the policy research, it has reached agreements below:

A. It should be improve the integration of the supervision, aiming to the every department of the architecture market management closed and independence, it also should deepen the architecture market management reform, transform the government function, consummate the supervision system, enhance the harmonize management between different department, improve the supervision integration.

B. Breeding architecture market credibility system, establishing the self-restricting mechanism through building credit rewarding and punishing system.

C. Improve supervision efficiency, reduce the manage cost, implement difference supervision system, in architecture market management, according to different situations, different intensions difference supervisions are implemented[4][5].

There into, difference supervision is the only way to improve the administration efficiency and the supervision ability, and reduce the manage cost, but how to implement difference supervision system scientifically, it still lacks theoretical basis.

\section{BASIC VIEWPOINTS ABOUT BAYESIAN INFERENCE}

Basic viewpoints about Bayesian inference is that the unknown parameter of the population distribution is a random variable, which can be described by a probability distribution, which is known before sampling, and it is known as prior probability. Because each unknown parameter has uncertainty, the probability and the population distribution can express the uncertainty best. Bayesian inference is measure the truth of the uncertainty based on the probability or the population distribution [6]. 
III. PARAMETERS FORMULATION IN THE DIFFERENCE SUPERVISION THEORY OF ENGINEERING REGISTRATION WORKERS BASED ON BAYESIAN INFERENCE

The number of periods absent is a form of count data. Poisson regression is often used to analyze count data [7]. Poisson distribution is a special binomial distribution in which $\mathrm{n}$ is larger and $\mathrm{P}$ is smaller, and it is a distribution which describes the times of some result occurrences in $n$ experiments. The probability density function is

$$
P\{X=k\}=\frac{\lambda^{k} e^{-\lambda}}{k !}
$$

The absence level is used to verify an engineering registration worker whether an affiliated worker or not. The expectation of Poisson distribution is $\lambda$. The results show that if the absence level over $10 \%$, this level of absence is totally unacceptable, and if sustained, could undermine the future viability of the company. Urgent improvement is both essential and achievable [8].

Therefore, let $\omega_{2}$ define the event of which an engineering registration worker is not an affiliated worker, the absence level is $\lambda_{2}=0.05$, and corresponding $\omega_{1}$ is the event of which an engineering registration worker is an affiliated worker, the absence level is $\lambda_{1}=0.5$.According to inspection historical record and expert evaluation, it can define the probability of which an engineering registration worker is an affiliated worker is $20 \%$. So the prior probability can be obtained

$$
P\left(\lambda_{1}\right)=0.2, P\left(\lambda_{2}\right)=0.8 \text {. }
$$

Whereas, the inspection times $\mathrm{n}$ is not large, the likelihood function can be approximated by binomial distributed function

$$
\left(\begin{array}{l}
n \\
k
\end{array}\right) p^{k}(1-p)^{n-k}
$$

The posterior probability can be calculated by Bayesian formula

$$
P\left(\omega_{i} \mid B\right)=\frac{P\left(B \mid \omega_{i}\right) P\left(\omega_{i}\right)}{\sum_{i=1}^{4} P\left(B \mid \omega_{i}\right) P\left(\omega_{i}\right)},
$$

Where the event is $\omega_{i}$, and the state is $B$. It can provide theoretical basis for the difference supervision.

\section{THE BAYESIAN INFERENCE INSTANCE OF ENGINEERING REGISTRATION WORKER DIFFERENCE SUPERVISION}

A case of the first Bayesian inference for 3 times inspection, 3 times inspection absence levels of each project are shown in table 1 . Form the results, if there is no absence in 3 times inspection, the modified posterior probability shows that the probability of an affiliated worker is only $3.5 \%$, so it can not be defined as affiliated, it should depress supervision level. If there is 1 time absence, the modified posterior probability shows that the probability of an affiliated worker is $39.7 \%$, so it can not be defined as affiliated in high probability, it need suitability increase supervision level. If there are 2-3 times absences, the modified posterior probability shows that the probability of an affiliated worker is over $93 \%$, so it can be defined as affiliated, it can increase supervision level to highest or be punished directly.

TABLE I. 3 TIMES INSPECTION ABSENCE LEVELS OF EACH PROJECT

\begin{tabular}{|c|c|c|c|c|c|c|}
\hline $\begin{array}{c}\text { practical } \\
\text { inspection } \\
\text { absence } B\end{array}$ & $\begin{array}{c}\text { whether an } \\
\text { affiliated } \\
\text { worker } \omega_{i}\end{array}$ & $\begin{array}{c}\text { absence } \\
\text { level } \\
\text { expectation }\end{array}$ & $\begin{array}{c}\text { prior } \\
\text { probability }\end{array}\left(\omega_{i}\right)$ & $P\left(B \mid \omega_{i}\right)$ & $P\left(B \mid \omega_{i}\right) P\left(\omega_{i}\right)$ & $\begin{array}{c}\text { posterior } \\
\text { probability } P\left(\omega_{i} \mid B\right)\end{array}$ \\
\hline \multirow{2}{*}{0} & $\omega_{1}$ yes & $\lambda_{1}=0.5$ & $P\left(\omega_{1}\right)=0.2$ & 0.125 & 0.025 & 0.035 \\
\cline { 2 - 7 } & $\omega_{2}$ no & $\lambda_{2}=0.05$ & $P\left(\omega_{2}\right)=0.8$ & 0.857 & 0.686 & 0.965 \\
\hline \multirow{2}{*}{1} & $\omega_{1}$ yes & $\lambda_{1}=0.5$ & $P\left(\omega_{1}\right)=0.2$ & 0.375 & 0.075 & 0.397 \\
\cline { 2 - 7 } 2 & $\omega_{2}$ no & $\lambda_{2}=0.05$ & $P\left(\omega_{2}\right)=0.8$ & 0.1425 & 0.114 & 0.603 \\
\cline { 2 - 7 } & $\omega_{1}$ yes & $\lambda_{1}=0.5$ & $P\left(\omega_{1}\right)=0.2$ & 0.375 & 0.075 & 0.93 \\
\hline \multirow{2}{*}{3} & $\omega_{2}$ no & $\lambda_{2}=0.05$ & $P\left(\omega_{2}\right)=0.8$ & 0.007 & 0.0056 & 0.07 \\
\cline { 2 - 7 } & $\omega_{1}$ yes & $\lambda_{1}=0.5$ & $P\left(\omega_{1}\right)=0.2$ & 0.125 & 0.025 & 0.996 \\
\hline
\end{tabular}


For some workers needing more supervision to determine whether an affiliated worker, the prior posterior probability is used to be the prior probability. The results of workers that have 1 time absence in the first inspection and in the second inspection according absence level record making 3 times inspection, are shown in table 2. It shows that there is little difference between the results of $0,2,3$ times and 1 time absence level. But the workers who have 1 time absence, the posterior probability shows that the affiliated probability is $63.4 \%$. The supervision level can be more increased.

\section{THE FLOW DIAGRAM OF DIFFERENCE SUPERVISION THEORY OF ENGINEERING REGISTRATION WORKERS BASED ON BAYESIAN INFERENCE}

From the Bayesian inference instance of engineering registration worker difference supervision, the posterior probability of whether an affiliated worker can be obtained by Bayesian inference. Hence, the affiliated worker can be estimated. The flow diagram of difference supervision theory of engineering registration workers based on Bayesian inference is shown in fig. 1.

\section{RESUlts}

According inspection data, the prior probability is obtained, and based on Bayesian inference the posterior probability is calculated, so the estimation of whether an affiliated worker can be received. Consequently, the mathematical theoretical basis of the difference supervision is supplied. The scientific supervision method is provided for different intensity difference supervision.

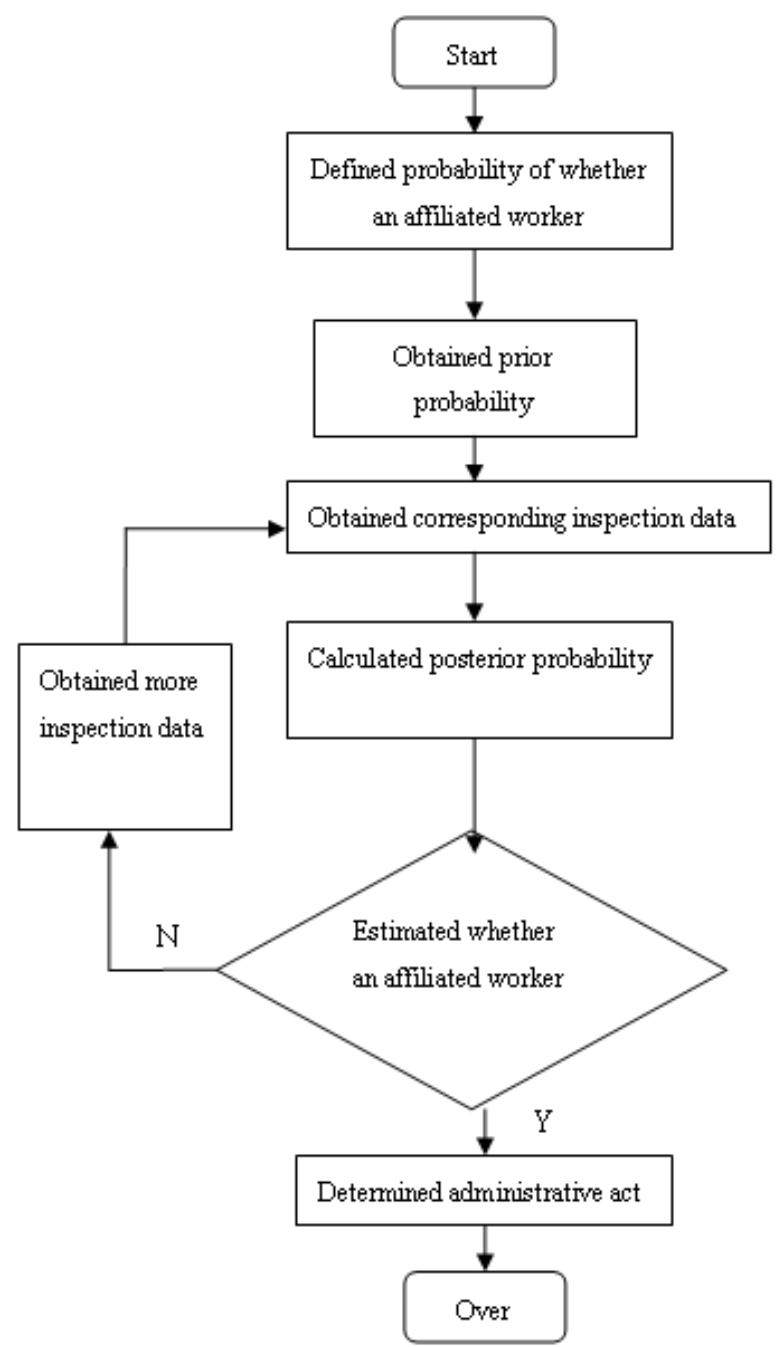

Figure 1. The flow diagram of difference supervision theory based on Bayesian inference.

TABLE II. THE SECOND INSPECTION OF DIFFERENT ABSENCE LEVEL RECORDS

\begin{tabular}{|c|c|c|c|c|c|c|}
\hline $\begin{array}{c}\text { practical } \\
\text { inspection } \\
\text { absence } B\end{array}$ & $\begin{array}{c}\text { whether an } \\
\text { affiliated worker } \\
\omega_{i}\end{array}$ & $\begin{array}{c}\text { absence level } \\
\text { expectation }\end{array}$ & $\begin{array}{c}\text { prior } \\
\text { probability } P\left(\omega_{i}\right)\end{array}$ & $P\left(B \mid \omega_{i}\right)$ & $P\left(B \mid \omega_{i}\right) P\left(\omega_{i}\right)$ & $\begin{array}{c}\text { posterior } \\
\text { probability } P\left(\omega_{i} \mid B\right)\end{array}$ \\
\hline \multirow{2}{*}{0} & $\omega_{1}$ yes & $\lambda_{1}=0.5$ & $P\left(\omega_{1}\right)=0.397$ & 0.125 & 0.0496 & 0.088 \\
\cline { 2 - 7 } & $\omega_{2}$ no & $\lambda_{2}=0.05$ & $P\left(\omega_{2}\right)=0.603$ & 0.857 & 0.5168 & 0.912 \\
\hline \multirow{2}{*}{1} & $\omega_{1}$ yes & $\lambda_{1}=0.5$ & $P\left(\omega_{1}\right)=0.397$ & 0.375 & 0.1489 & 0.634 \\
\hline \multirow{2}{*}{2} & $\omega_{2}$ no & $\lambda_{2}=0.05$ & $P\left(\omega_{2}\right)=0.603$ & 0.1425 & 0.0859 & 0.366 \\
\cline { 2 - 7 } & $\omega_{1}$ yes & $\lambda_{1}=0.5$ & $P\left(\omega_{1}\right)=0.397$ & 0.375 & 0.1489 & 0.972 \\
\hline \multirow{2}{*}{3} & $\omega_{2}$ no & $\lambda_{2}=0.05$ & $P\left(\omega_{2}\right)=0.603$ & 0.007 & 0.0042 & 0.028 \\
\cline { 2 - 7 } & $\omega_{1}$ yes & $\lambda_{1}=0.5$ & $P\left(\omega_{1}\right)=0.397$ & 0.125 & 0.0496 & 0.998 \\
\hline
\end{tabular}




\section{ACKNOWLEDGMENT}

We acknowledge the financial support provided by the 11th Five Years Key Programs for Science and Technology Development of China(2006BAJ16B01) and support by Ministry of Housing and Urban-Rural Development of the People’s Repnblic of China(2010-K5-11)

\section{REFERENCES}

[1] Guo zhiyi,Liu xueyi ,"The discussion of how to ensure engineering quality in construction engineer practicing”, construction engineering, pp. 212-215,August 2008

[2] Lei zhiguo,"The discussion of relation between construction engineer and project engineer”, pp. 110-113,urban roads and bridges,December 2008
[3] http://www.tianya.cn/techforum/content/144/553413.shtml

[4] Huangwei,"Promoting supervise innovations,Improve supervise efficiency, break new ground of supervision work for markets of construction", markets of construction bid and tender, pp. 4-10 January 2007

[5] Ministry of Construction.”Market integrity of national building information platform has enabled", engineering installation, pp. 57,February 2008

[6] Cheng xiru,"the review and outlook of statistics”, Statistical Research, pp.27-32,February 2000

[7] Aitken M, Anderson D, Francis B, Hinde J ," Statistical Modelling in GLIM”,New York Oxford University Press, pp. 217-225,1989.

[8] Michael Fitzpatrick,Andrzej Huczynski,”Applying the Benchmarking Approach to Absence Control”, LEADERSHIP \& ORGANIZATION DEVELOPMENT Vol. 11, pp. 22-26 